\title{
PENERAPAN MODEL HYBRID ARIMA BACKPROPAGATION UNTUK PERAMALAN HARGA GABAH INDONESIA
}

\author{
Sufia Nur Janah ${ }^{1}$, Winita Sulandari ${ }^{2}$, Santoso Budi Wiyono ${ }^{2}$ \\ ${ }^{2}$ Dosen Jurusan Matematika FMIPA UNS \\ winita@mipa.uns.ac.id
}

\begin{abstract}
Hybrid model discussed in this paper combining ARIMA and backpropagation is applied to grain price forecasting in Indonesia for period January 2008 until April 2013. The grain price time series consists of linear and nonlinear patterns. Backpropagations can recognize non linear patterns that can not be done by ARIMA. In order to find the best model, some combinations of prepocessing transformations, the number of input and hidden units, and the activation function were applied in the contruction of the network structure. Based on the experiments, it can be showed that ARIMA backpropagation hybrid model provides more accurate results than ARIMA model. The hybrid model would rather be used in the short-term forecasting, no more than three periods.
\end{abstract}

Keywords: ARIMA, Backpropagation, Hybrid, Grain Price

\section{Pendahuluan}

Yule pada tahun 1927 memperkenalkan model Autoregressive (AR) untuk meramalkan bilangan tahunan sunspot ${ }^{[2]}$. Kemudian Box dan Jenkins ${ }^{[2]}$ mengembangkan model Autoregressive Integrated Moving Average (ARIMA) sebagai prosedur standar untuk pemodelan runtun waktu linear. Dalam perkembangan analisis runtun waktu, telah banyak diketahui bahwa secara umum fenomena yang terjadi dalam kehidupan sehari-hari mempunyai hubungan nonlinear ${ }^{[8]}$. Dalam menyelesaikan permasalahan runtun waktu nonlinear digunakan model jaringan syaraf tiruan (JST) $)^{[1]}$. Fausett ${ }^{[4]}$ menyatakan bahwa JST adalah sistem pemrosesan informasi yang mempunyai karakteristik mirip dengan jaringan syaraf biologi. Metode dari JST yang sering diterapkan dalam bidang peramalan adalah backpropagation. Zhang ${ }^{[10]}$ memperkenalkan peramalan runtun waktu menggunakan model hybrid ARIMA backpropagation (BP). Model hybrid ARIMA BP dapat mengatasi data yang berpola campuran linear dan nonlinear.

Berdasarkan uraian yang telah disampaikan, penulis tertarik untuk mengkaji ulang metode hybrid ARIMA backpropagation dan menerapkannya untuk peramalan harga Gabah Kering Giling (GKG) tingkat petani di Indonesia periode Januari 2008 - April 2013. GKG merupakan kriteria gabah dengan kualitas kadar air maksimum 14\% dan kadar hampa maksimum 3\% ${ }^{[3]}$. Dalam penyusunan struktur JST diterapkan empat transformasi pada preprocessing serta mengkombinasikan 1-5 unit masukan dan menerapkan dua fungsi aktivasi log sigmoid dan tan sigmoid pada kombinasi 1-15 unit lapisan tersembunyi.

\section{Autoregressive Integrated Moving Average (ARIMA)}

Dalam model umum $\operatorname{ARIMA}(p, d, q)$ yang diperkenalkan oleh Box dan Jenkins ${ }^{[2]}$, nilai variabel yang akan datang diasumsikan merupakan fungsi linear dari beberapa observasi terdahulu dan residu random. Model runtun waktu yang dimaksud mempunyai bentuk

$$
(1-B)^{d} z_{t}=w_{t}=\phi_{1} w_{t-1}+\cdots+\phi_{p} w_{t-p}+\varepsilon_{t}-\theta_{1} \varepsilon_{t-1}-\cdots-\theta_{q} \varepsilon_{t-q}
$$

dengan $z_{t}$ nilai aktual pada periode waktu ke- $t, w_{t}$ adalah pembedaan ke- $d$ dari nilai 
aktual pada periode waktu ke- $t, B$ adalah operator mundur, $\varepsilon_{t}$ residu random pada periode waktu ke- $t, \varepsilon_{t} \sim$ iid $N\left(0, \sigma^{2}\right), \phi_{i}$ adalah parameter model $A R(p)$, dan $\theta_{j}$ adalah parameter model $M A(q)$. Persamaan (1) dapat dipersempit menjadi kasus khusus dari model ARIMA. Jika $q=0$ maka Persamaan (1) menjadi model $A R I$ atau $\operatorname{ARIMA}(p, d, 0)$. Jika $p=0$ maka Persamaan (1) dipersempit menjadi model $\operatorname{IMA}$ atau $\operatorname{ARIMA}(0, d, q)^{[2]}$.

\section{Backpropagation}

Backpropagation merupakan salah satu pelatihan terawasi yaitu dalam proses pengenalan pola atau penyesuaian bobot memerlukan target untuk mencapai nilai kesalahan minimum dari keluaran jaringan ${ }^{[4]}$. Zhang ${ }^{[10]}$ menyatakan hubungan antara keluaran $y_{t}$ dan masukan $y_{t-1}, y_{t-2}, \ldots, y_{t-p}$ dinyatakan sebagai

$$
y_{t}=\alpha_{0}+\sum_{j=1}^{q} \alpha_{j} g\left(\beta_{0 j}+\sum_{i=1}^{p} \beta_{i j} y_{t-i}\right)+\varepsilon_{t}
$$

dengan $\alpha_{j}(j=0,1,2, \ldots, q)$ dan $\beta_{i j}(i=0,1,2, \ldots, p ; j=1,2, \ldots, q)$ adalah parameter model yang disebut dengan bobot penghubung, $p$ adalah jumlah unit masukan dan $q$ adalah jumlah unit tersembunyi. Kemudian $g$ dalam Persamaan (2) adalah fungsi aktivasi pada lapisan tersembunyi. Dalam penelitian ini digunakan algoritma backpropagation dengan metode optimasi Levenberg-Marquardt yang mengacu pada Lourakis ${ }^{[6]}$.

\section{Hybrid ARIMA Backpropagation}

Model hybrid ARIMA backpropagation merupakan gabungan model ARIMA dan backpropagation. Runtun waktu yang tersusun terdiri dari struktur autokorelasi linear dan nonlinear, sehingga dapat direpresentasikan dalam bentuk

$$
y_{t}=L_{t}+N_{t}
$$

dengan $L_{t}$ merupakan komponen linear dan $N_{t}$ merupakan komponen nonlinear. ARIMA digunakan untuk memodelkan komponen linear, kemudian residu dari komponen linear hanya berisi hubungan nonlinear. Memodelkan residu menggunakan JST dapat mengatasi komponen nonlinear dalam data ${ }^{[10]}$. Model residunya dapat ditulis dalam bentuk

$$
e_{t}=f\left(e_{t-1}, e_{t-2}, \ldots, e_{t-n}\right)+\varepsilon_{t}
$$

dengan $e_{t}$ merupakan residu model ARIMA, $f$ merupakan fungsi nonlinear yang ditentukan menggunakan backpropagation dan $\varepsilon_{t}$ merupakan eror random. Persamaan (3) dapat ditulis dalam bentuk

$$
e_{t}=\alpha_{0}+\sum_{j=1}^{q} \alpha_{j} g\left(\beta_{0 j}+\sum_{i=1}^{p} \beta_{i j} e_{t-i}\right)+\varepsilon_{t}
$$

dengan $g$ merupakan fungsi aktivasi yang digunakan dalam lapisan tersembunyi yaitu log sigmoid dan tan sigmoid. Dalam penyusunan struktur jaringan digunakan transformasi pada preprocessing, yaitu $e_{t}{ }^{\prime}=\left[\frac{e_{t}-e_{\min }}{e_{\operatorname{maks}}-e_{\min }}(a-b)\right]+b, e_{t}{ }^{\prime}=e_{t}$, dan $e_{t}{ }^{\prime}=\frac{e_{t}-e_{\text {rata-rata }}}{e_{\text {standar deviasi }}}$, dengan $a$ sebagai nilai tertinggi interval dan $b$ sebagai nilai terendah interval.

\section{Metode Penelitian}

Metode yang digunakan adalah subjek literatur Zhang ${ }^{[10]}$, selanjutnya dilakukan penerapan hybrid ARIMA BP pada data harga gabah Indonesia yang diperoleh dari www.bps.go.id. Beberapa tahapan penelitian adalah mengkaji ulang terkait ARIMA, JST, dan hybrid serta menyusun prosedur hybrid ARIMA backpropagation yang meliputi tahap pemodelan ARIMA dan JST. Residu model ARIMA yang tidak memenuhi uji independensi digunakan sebagai masukan untuk algoritma backpropagation dengan metode optimasi Levenberg-Marquardt. Dalam mencari model terbaik pada struktur JST, dilakukan preprocessing dengan empat transformasi serta diterapkan dua fungsi aktivasi log sigmoid 
dan tan sigmoid pada lapisan tersembunyi. Mengkombinasikan 1-5 unit masukan dan 1-15 unit lapisan tersembunyi. Selanjutnya, melakukan pelatihan pada semua kombinasi struktur jaringan dan pengujian terhadap data uji, yaitu residu ARIMA harga gabah GKG Indonesia periode Mei - Desember 2013. Struktur jaringan dengan nilai Mean Squared Error (MSE) terkecil pada saat pengujian digunakan untuk peramalan.

\section{Hasil Penelitian dan Pembahasan}

Data penelitian yang digunakan adalah data runtun waktu tiap bulan harga gabah GKG Indonesia periode Januari 2008 - April 2013.

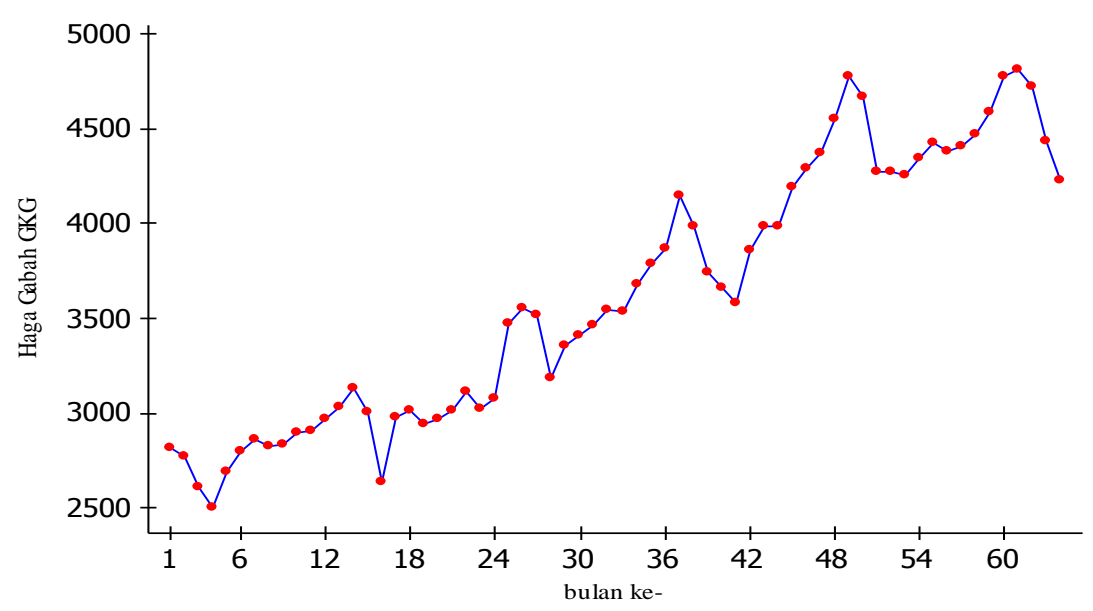

Gambar 1. Plot Runtun Waktu Harga Gabah GKG Indonesia Januari 2008 - April 2013

Berdasarkan Gambar 1, data harga gabah mempunyai pola linear untuk beberapa periode waktu, misal pada bulan Agustus 2008 - Januari 2009 menggunakan uji linearitas Harvey-Collier dengan $\alpha=0,05$ memberikan hasil bahwa data mempunyai hubungan linear. Kemudian, dilakukan uji linearitas untuk data keseluruhan memberikan hasil bahwa data mempunyai hubungan nonlinear. Selanjutnya, model hybrid ARIMA BP dapat diterapkan dalam data harga gabah GKG Indonesia periode Januari 2008 - April 2013, karena data mengandung pola linear dan nonlinear.

\subsection{Penyusunan Model ARIMA}

Penyusunan model ARIMA membutuhkan beberapa tahapan, yaitu identifikasi model, estimasi parameter, dan uji diagnostik model. Dalam pengidentifikasian model ARIMA diperiksa kestasioneran data runtun waktu terlebih dahulu. Hasil penelitian menunjukkan bahwa data tidak stasioner sehingga perlu dilakukan pembedaan. Kemudian, dilakukan uji akar-akar unit Augmented Dickey-Fuller dan Phillips-Perron pada data pembedaan orde satu. Kedua uji ini memberikan hasil bahwa data pembedaan orde satu sudah stasioner. Selanjutnya, model ARIMA dapat diidentifikasi dengan membandingkan distribusi teoritis dari grafik $A C F$ dan $P A C F$. Diperoleh model awal yaitu ARIMA $([6,9,12], 1,0)$ dan ARIMA $(0,1,[9,12])$. Model ARIMA $([6,9,12], 1,0)$ dan ARIMA $(0,1,[9,12])$ merupakan contoh model subset ARIMA. McClave mengembangkan prosedur pendekatan proses stasioner dengan membuat subset $A R^{[7]}$. Menurut F.J. Ojo dan T.O. Olatayo, subset ARIMA merupakan himpunan bagian dari model ARIMA, sehingga tidak dapat dinyatakan dalam bentuk umum ${ }^{[9]}$. Model ARIMA $([6,9,12], 1,0)$ dapat ditulis sebagai

$$
\left(1-\phi_{6} B^{6}-\phi_{9} B^{9}-\phi_{12} B^{12}\right) w_{t}=\varepsilon_{t} .
$$


Diperoleh model yang memenuhi signifikansi model yaitu ARIMA $([9,12], 1,0)$ tanpa intercept dapat ditulis sebagai

$$
w_{t}=\varepsilon_{t}-0,2241511 w_{t-9}+0,58027532 w_{t-12},
$$

dan ARIMA $(0,1,[12])$ tanpa intercept dapat ditulis sebagai

$$
z_{t}=z_{t-1}+\varepsilon_{t}+0,728309078 \varepsilon_{t-12} \text {. }
$$

Karena $\left|\phi_{9}\right|<1,\left|\phi_{12}\right|<1,\left|\theta_{9}\right|<1$, kedua model stasioner.

Uji diagnostik residu $\varepsilon_{t}$ memberikan hasil bahwa uji normalitas dan homogenitas variansi pada masing-masing model terpenuhi, namun hasil uji independensi memperlihatkan bahwa residu model $\operatorname{IMA}(1,[12])$ tidak independen sedangkan residu model $A R I([9,12], 1)$ independen.

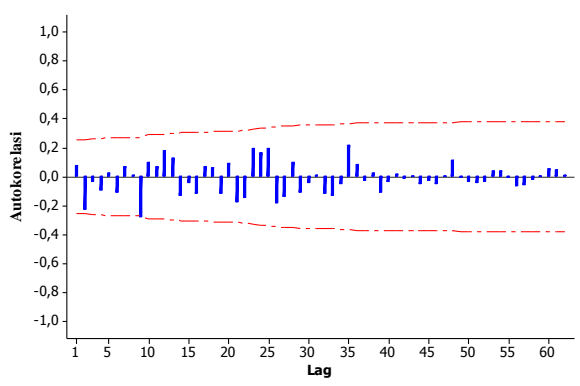

(a)

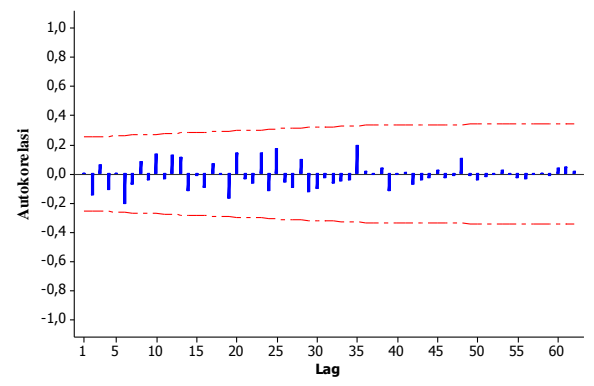

(b)

Gambar 2. (a) $A C F$ model $I M A(1,[12])$ dan (b) $A R I([9,12], 1)$

\subsection{Model Jaringan Syaraf Tiruan}

Pada penelitian ini model ARIMA yang telah memenuhi uji independensi tidak dilanjutkan pada tahap pemodelan JST, karena sudah memenuhi uji kelayakan model. Sedangkan, residu ARIMA yang tidak memenuhi uji independensi yaitu IMA (1,[12]) dapat dimodelkan lagi menggunakan JST, karena tidak ada asumsi statistik untuk masukan JST. Tahap-tahap yang dilakukan dalam pemodelan JST meliputi pelatihan dan pengujian jaringan serta memilih struktur jaringan optimum.

Pada penelitian ini dilakukan pelatihan masing-masing jaringan yang terdiri atas kombinasi 1-5 unit masukan, 1-15 unit lapisan tersembunyi, dan satu unit keluaran. Preprocessing untuk masing-masing masukan menggunakan beberapa transformasi yaitu $e_{t}{ }^{\prime}=\left[\frac{e_{t}-e_{\min }}{e_{\text {maks }}-e_{\min }}(a-b)\right]+b, \quad e_{t}{ }^{\prime}=e_{t}, \quad$ dan $\quad e_{t}{ }^{\prime}=\frac{e_{t}-e_{\text {rata-rata }}}{e_{\text {standar deviasi }}} . \quad$ Transformasi $e_{t}{ }^{\prime}=\left[\frac{e_{t}-e_{\min }}{e_{\operatorname{maks}}-e_{\min }}(a-b)\right]+b$ diterapkan dengan dua perlakuan, yang pertama adalah mengganti nilai a dan $\mathrm{b}$ dengan masing-masing -1 dan 1 . Perlakuan ke-2 adalah mengganti nilai a dan $b$ sesuai dengan fungsi aktivasinya pada lapisan tersembunyi, jika log sigmoid maka nilai a dan b diganti dengan 0,1 dan 0,9 , jika fungsi aktivasinya tan sigmoid maka nilai a dan $b$ diganti dengan $-0,9$ dan 0,9 . Kemudian menerapkan fungsi aktivasi log sigmoid dan tan sigmoid pada lapisan tersembunyi, dan fungsi aktivasi linear pada lapisan keluaran. Pelatihan menggunakan algoritma backpropagation dengan metode optimasi Levenberg-Marquardt dilakukan sebanyak 600 model (4 transformasi x 5 unit masukan $\mathrm{x}$ 15 unit lapisan tersembunyi x 2 fungsi aktivasi). Kriteria jaringan yang akan digunakan untuk proses pengujian adalah jaringan yang mempunyai nilai $M S E$ kurang dari $1 \times 10^{-5}$ dan iterasi maksimum sebanyak 100.000 iterasi pada proses pelatihan, diperoleh 94 jaringan yang memenuhi kriteria. Hasil pelatihan dengan MSE terkecil ditampilkan dalam Tabel 1. 
Tabel 1. Hasil Pelatihan MSE Terkecil

\begin{tabular}{|c|c|c|c|c|c|c|c|c|}
\hline \multirow{2}{*}{$\begin{array}{c}\text { LOG } \\
\text { SIGMOID }\end{array}$} & \multicolumn{2}{|c|}{ Linear } & \multicolumn{2}{|c|}{ Min-max $[-1,1]$} & \multicolumn{2}{|c|}{ Min-max $[0,1 ; 0,9]$} & \multicolumn{2}{|c|}{ Mean-std } \\
\hline & $\begin{array}{c}\text { Struktur } \\
5-15-1\end{array}$ & $\begin{array}{c}M S E \\
5982,53 \\
\end{array}$ & $\begin{array}{c}\text { Struktur } \\
5-15-1\end{array}$ & $\begin{array}{c}M S E \\
0,54291\end{array}$ & $\begin{array}{c}\text { Struktur } \\
5-14-1 \\
\end{array}$ & $\begin{array}{c}M S E \\
0,00152\end{array}$ & $\begin{array}{l}\text { Struktur } \\
5-12-1 \\
\end{array}$ & 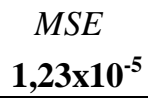 \\
\hline \multirow{2}{*}{$\begin{array}{c}\text { TAN } \\
\text { SIGMOID }\end{array}$} & \multicolumn{2}{|c|}{ Linear } & \multicolumn{2}{|c|}{ Min-max $[-1,1]$} & \multicolumn{2}{|c|}{ Min-max $[-0,9 ; 0,9]$} & \multicolumn{2}{|c|}{ Mean-std } \\
\hline & $\begin{array}{c}\text { Struktur } \\
2-14-1\end{array}$ & $\begin{array}{c}M S E \\
6092,63\end{array}$ & $\begin{array}{c}\text { Struktur } \\
5-14-1\end{array}$ & $\begin{array}{c}M S E \\
0,00016\end{array}$ & $\begin{array}{c}\text { Struktur } \\
5-13-1\end{array}$ & $\begin{array}{c}M S E \\
0,00042\end{array}$ & $\begin{array}{c}\text { Struktur } \\
4-15-1\end{array}$ & $\begin{array}{c}M S E \\
2,41 \times 10^{-5}\end{array}$ \\
\hline
\end{tabular}

Diperoleh bahwa MSE transformasi linear cenderung lebih besar dibandingkan $M S E$ tiga transformasi lainnya. Fungsi aktivasi log sigmoid memberikan MSE yang lebih kecil dibandingkan $M S E$ fungsi aktivasi tan sigmoid untuk transformasi mean-standar deviasi dan linear pada preprocessing. Selanjutnya, melakukan pengujian jaringan pada data out sample periode Mei-Desember 2013. Preprocessing dengan transformasi linear tidak digunakan untuk tahap pengujian, karena $M S E$ struktur jaringan yang dihasilkan pada saat pelatihan tidak memenuhi batas $M S E$ toleransi. Hasil pengujian dengan MSE terkecil ditampilkan pada Tabel 2.

Tabel 2. Hasil Pengujian MSE Terkecil

\begin{tabular}{ccccccc}
\hline \multirow{2}{*}{ LOG } & \multicolumn{2}{c}{ Min-max $[-1,1]$} & \multicolumn{2}{c}{ Min-max [0,1;0,9] } & \multicolumn{2}{c}{ Mean-std } \\
\cline { 2 - 7 } SIGMOID & Struktur & $M S E$ & Struktur & $M S E$ & Struktur & $M S E$ \\
& $5-13-1$ & $22.147,69$ & $5-11-1$ & $19.390,293$ & $5-14-1$ & $12.619,95$ \\
\hline \multirow{2}{*}{ TAN } & \multicolumn{2}{c}{ Min-max $[-1,1]$} & \multicolumn{2}{c}{ Min-max $[-0,9 ; 0,9]$} & \multicolumn{2}{c}{ Mean-std } \\
\cline { 2 - 7 } SIGMOID & Struktur & $M S E$ & Struktur & $M S E$ & Struktur & $M S E$ \\
& $4-12-1$ & $6.027,335$ & $4-12-1$ & $39.158,901$ & $\mathbf{5 - 1 4 - 1}$ & $\mathbf{3 . 0 1 2 , 1 3 1}$ \\
\hline
\end{tabular}

Jaringan optimum adalah jaringan yang memiliki nilai $M S E$ terkecil dari proses pengujian, yaitu 3.012,131 pada struktur jaringan 5-14-1 dengan transformasi meanstandar deviasi pada preprocessing dan fungsi aktivasi pada lapisan tersembunyi adalah tan sigmoid. Struktur jaringan 5-14-1 ditunjukkan pada Gambar 3, sedangkan bobot-bobot yang menghubungkan antar neuron disajikan pada Tabel 3a dan Tabel $3 b$.

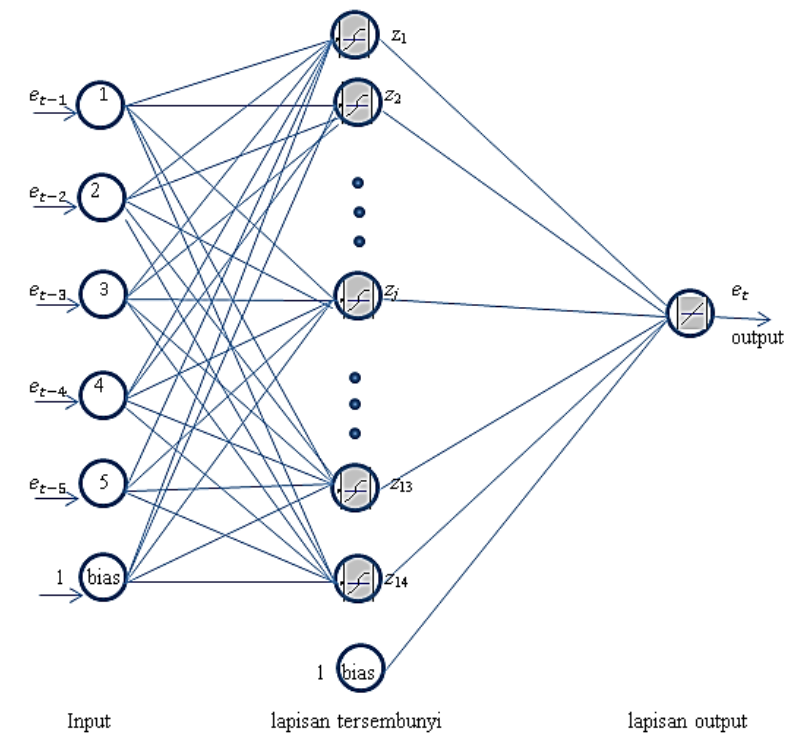

Gambar 3. Struktur Jaringan 5-14-1 
Tabel 3a. Bobot-bobot yang Menghubungkan Setiap Unit Input ke Setiap Unit Tersembunyi

\begin{tabular}{|c|c|c|c|c|c|c|c|}
\hline & & \multicolumn{6}{|c|}{ Unit input ke-i } \\
\hline & & bias & 1 & 2 & 3 & 4 & 5 \\
\hline \multirow{14}{*}{ 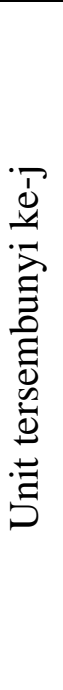 } & 1 & 1,29143 & 0,22163 & $-1,04599$ & $-0,45436$ & $-2,36647$ & 0,06400 \\
\hline & 2 & $-2,31598$ & 0,03767 & 0,28019 & 0,10874 & 0,11952 & 0,24903 \\
\hline & 3 & $-2,23060$ & 0,13470 & $-0,65003$ & 0,24368 & 0,14376 & 0,62266 \\
\hline & 4 & 1,49362 & $-1,73356$ & $-0,56813$ & $-0,74823$ & $-0,89082$ & $-0,27406$ \\
\hline & 5 & $-0,97612$ & $-0,25873$ & $-2,17971$ & 0,08384 & $-0,28544$ & $-1,28027$ \\
\hline & 6 & 0,52185 & $-2,42077$ & 0,65521 & $-2,17990$ & $-0,52197$ & 0,38865 \\
\hline & 7 & 1,56028 & 2,53808 & $-0,04340$ & 0,77992 & $-0,98192$ & $-0,25501$ \\
\hline & 8 & $-0,86022$ & $-1,07444$ & $-1,64745$ & 0,72362 & $-0,14797$ & $-1,58169$ \\
\hline & 9 & $-1,86094$ & 0,21638 & $-0,54577$ & 2,04535 & $-1,46381$ & $-2,40980$ \\
\hline & 10 & $-0,66200$ & $-0,15931$ & $-1,26031$ & $-0,10195$ & 1,79370 & $-2,22258$ \\
\hline & 11 & $-0,97002$ & 0,05703 & 0,66806 & $-1,81304$ & $-1,80973$ & 1,18509 \\
\hline & 12 & 2,34888 & 0,75101 & $-1,24187$ & $-1,57429$ & $-1,57429$ & 0,37448 \\
\hline & 13 & $-3,10055$ & $-0,89406$ & 0,08281 & $-0,70930$ & $-0,70930$ & 0,17606 \\
\hline & 14 & $-3,41945$ & $-3,26932$ & 0,17935 & $-0,10730$ & $-0,10730$ & $-1,11893$ \\
\hline
\end{tabular}

Tabel 3b. Bobot-bobot yang Menghubungkan Setiap Unit Tersembunyi ke Unit Keluaran

\begin{tabular}{cccccccccccccccc}
\hline & \multicolumn{11}{c}{ Unit tersembunyi ke-j } \\
\cline { 2 - 13 } & bias & 1 & 2 & 3 & 4 & 5 & 6 & 7 & 8 & 9 & 10 & 11 & 12 & 13 & 14 \\
\hline $\begin{array}{c}\text { Unit } \\
\text { keluaran }\end{array}$ & $-0,1255$ & $-1,6692$ & 0,3817 & 0,2786 & 2,7878 & 1,7000 & $-2,2770$ & 2,7264 & 1,5697 & $-2,3815$ & 1,0833 & 1,4630 & 2,0127 & 1,3525 & 3,1933 \\
\hline
\end{tabular}

Peramalan data asli pada bulan Januari - Maret 2014 menggunakan model hybrid diberikan pada Tabel 4.

Tabel 4. Peramalan Harga Gabah GKG

\begin{tabular}{cc}
\multicolumn{2}{c}{ Tingkat Petani Indonesia } \\
\hline Peramalan & Aktual \\
\hline $4.834,91$ & $4.776,26$ \\
$4.763,94$ & $4.791,95$ \\
$4.696,10$ & $4.790,71$ \\
\hline
\end{tabular}

Diperoleh bahwa MSE peramalan model hybrid sebesar 4.391,82 dan MSE peramalan model ARI $([9,12], 1)$ sebesar 15.930,47.

\section{Kesimpulan}

Pada penelitian ini dapat diambil kesimpulan bahwa MSE pelatihan struktur jaringan pada preprocessing dengan transformasi linear cenderung lebih besar dibandingkan dengan MSE pada transformasi minimum-maksimum dan mean-standar deviasi. Fungsi aktivasi pada lapisan tersembunyi log sigmoid memberikan $M S E$ yang lebih kecil dibandingkan $M S E$ fungsi aktivasi tan sigmoid untuk transformasi mean-standar deviasi dan linear pada preprocessing. Pada penelitian ini, model terbaik yang digunakan untuk meramalkan data harga gabah adalah model hybrid ARIMA $(0,1,[12])$ BP dengan struktur jaringan 5-14-1 dengan transformasi mean-standar deviasi pada preprocessing dan fungsi aktivasi pada lapisan tersembunyi adalah tan sigmoid. Struktur jaringan yang dipilih memberikan arti 
bahwa peramalan residu hasil transformasi mean-standar deviasi pada masa sekarang didekati oleh residu transformasi lima bulan sebelumnya serta fungsi yang menggambarkan hubungan antar residu adalah fungsi nonlinear tan sigmoid. Hasil peramalan untuk periode Januari - Maret 2014 menggunakan model hybrid ARIMA (0,1,[12]) $B P$ adalah 4.834,91, 4.763,94, dan 4.696,10.

\section{DAFTAR PUSTAKA}

1. Allende, H., C. Moraga, and R. Salas., Artificial Neural Networks in Time Series Forecasting: A Comparative Analysis, Kybernetika, 2002, Vol. 38, No. 6: 685-707.

2. Box, G.E.P. and G. Jenkins, Time Series Analysis, Forecasting and Control, HoldenDay, San Francisco, 1994.

3. Bulog, Kebijakan Perberasan. Instruksi Presiden, No. 3, 2012

4. Fausett, L., Fundamentals of Neural Networks: Architechture, Algoritms, and Applications, Prentice Hall, New Jersey, 1994.

5. Hanke, J.W.E. and D. Wichern, Business Forecasting, Pearson Education, Inc., 2005.

6. Lourakis, M.I.A., A Brief Description of The Levenberg-Marquardt Algorithm Implemened by levmar. Institute of Computer Science Greece, 2005, http://www.ics.forth.gr/ lourakis/levmar.

7. Spreen T.H., Mayer R.E., Simpson J.R. and McClave J.T., Forecasting monthly slaughter cow prices with subset autoregressive model, Southern Journal of Agricultural Economics, 1979, No. 1751: 126-131.

8. Suhartono, Feedforward Neural Networks Untuk Pemodelan Runtun waktu, Disertasi UGM, Yogyakarta, 2007.

9. Tarno, Kombinasi Prosedur Pemodelan Subset Arima dan Deteksi Outlier Untuk Prediksi Data Runtun Waktu, Prosiding Seminar Nasional Statistika UNDIP, 2013.

10. Zhang, G.P., Time Series Forecasting using a Hybrid ARIMA and Neural Networks Model, Neurocomputing, 2003, 50: 159-175. 